\title{
Dynamic electricity tariff definition based on market price, consumption and renewable generation patterns
}

\author{
Catarina Ribeiro ${ }^{1,2}$, Tiago Pinto ${ }^{3}$, Pedro Faria ${ }^{1}$, Sergio Ramos ${ }^{1}$, Zita Vale ${ }^{4}$, José Baptista ${ }^{2,5}$ João Soares $^{1}$, Maria Navarro- \\ Caceres $^{3}$, Juan Manuel Corchado ${ }^{3,6}$ \\ ${ }^{1}$ GECAD research group, Polytechnic of Porto (ISEP/IPP), Porto, Portugal \\ ${ }^{2}$ UTAD - Universidade de Trás-os-Montes e Alto-Douro \\ ${ }^{3}$ BISITE research group, University of Salamanca, Salamanca, Spain \\ ${ }^{4}$ Polytechnic of Porto, Porto, Portugal \\ ${ }^{5} \mathrm{CPES}$ - INESCTEC \\ ${ }^{6}$ Osaka Institute of Technology, Osaka, Japan
}

\begin{abstract}
The increasing use of renewable energy sources and distributed generation brought deep changes in power systems, namely with the operation of competitive electricity markets. With the eminent implementation of micro grids and smart grids, new business models able to cope with the new opportunities are being developed. Virtual Power Players are a new type of player, which allows aggregating a diversity of entities, e.g. generation, storage, electric vehicles, and consumers, to facilitate their participation in the electricity markets and to provide a set of new services promoting generation and consumption efficiency, while improving players` benefits. In order to achieve this objective, it is necessary to define tariff structures that benefit or penalize agents according to their behavior. In this paper a method for determining the tariff structures has been proposed, optimized for different load regimes. Daily dynamic tariff structures were defined and proposed, on an hourly basis, 24 hours day-ahead from the characterization of the typical load profile, the value of the electricity market price and considering the renewable energy production.
\end{abstract}

Index Terms - Data mining, load profiling, electricity tariffs, dynamic pricing.

\section{INTRODUCTION}

The restructuring of the electricity sector led to the end of regulated monopolies and the introduction of free competition, particularly in the production and commercialization of electricity, with new market players emerging. In the scope of these markets, electricity customers are free to choose and switch suppliers, because of possible economic advantages. Potential benefits will depend on the efficient operation in the market and, on the other hand, the remuneration of aggregated players. Important developments concerning electricity market players modelling and simulation including decision-support capabilities can be widely found in the literature [1-2]. Electricity tariff, is commonly known as the price at which electricity is supplied and sold under a contract to a particular consumer. The structure and types of electricity tariffs may vary from country to country. In countries where liberalized market mechanisms are introduced, trading companies compete with each other offering differentiated prices for the sale of

This work has received funding from the European Union's Horizon 2020 research and innovation programme under the Marie Sklodowska-Curie grant agreement No 641794 (project DREAM-GO); and from FEDER Funds through COMPETE program and from National Funds through FCT under the project UID/EEA/00760/2013 electricity. In other circumstances, the price range for electricity tariffs is structured in accordance with a particular government agency, normally charged with the supervision of prices within that jurisdiction.

The introduction of Time-of-use (TOU) tariffs, such as biand tri-hour tariffs for low voltage (LV) consumers, or tetrahour tariffs for LV consumers, medium voltage (MV), high voltage (HT) - transient sales tariffs to final customers to be applied by last resort vendors in the Portuguese case - help to encourage consumers to change their standard consumption and thus be compensated by the effort of this change. However, this is a time-of-use tariff that varies in a pre-established and systematic way, throughout the day and on the days of the week, which has never been altered in order to reflect the balance of the system between supply and demand on a daily basis [3]. In this time interval the tariff has the same value, the step ahead is to become possible for the consumer to check the instantaneous value of the electricity sales tariff and decide whether or not to put the most diverse loads into operation. Thus, with the introduction of smart meters in general consumers (as is already the case with industrial customers), and in a typical market environment, information regarding the value of the electric energy sales tariff may be made available to the customer real time [4]. There is an unprecedented paradigm shift in the consumption of electricity. The consumer will cease to be a passive agent to become an active agent with decision-making power.

This paper proposes a methodology for the dynamic definition of optimized tariff structures, with the objective of defining the best tariff to be applied to a particular set of consumers, previously characterized, and coming from the process of discovery of knowledge contained in databases from previous studies. The methodology takes into account not only the typical profile of consumers, but also the value of the electricity market price and the generation from renewable energy. In this way, it is possible to define intelligent and dynamic tariffs that contribute to reducing consumption peaks, increase the use of renewable energy, and reflect the wholesale market prices on the end consumer. 


\section{Electricuty TARIFF StRUCTURE}

Conceptually, electricity tariff, is the price at which electricity is supplied. Basically, the tariff is the revenue source of the electric power supply company, which usually include a return on investment goal as well as recovery of operating costs. In the regulated market, the setting of tariffs to be paid by final consumers is stipulated by a regulatory entity, and is normally a tax imposed annually. In a liberalized market environment, the various trading companies may compete freely in terms of prices and commercial conditions offered, in accordance with the rules of competition, general law and applicable regulations. The process of liberalization of the energy market refers only to the commercialization activity, since the transportation and distribution of electric energy continue to be activities carried out under a public service regime and exclusively because of their nature as natural monopolies. In both transport and distribution, third party access to the networks is guaranteed in conditions of transparency and non-discrimination, through proper regulation

Electricity tariffs types and structure vary considerably from country to country and from location to location. Several factors help determine the electricity tariff to be applied to a given location. One of the important aspects has to do with the cost of operation and maintenance of the power plants. In fact, the raw materials and the type of equipment used in the entire process of electric power generation has a direct effect on the costs to which electricity is sold to the final customer. It is common for companies or regulatory agencies (usually governmental) to request from the producing company's detailed documentation and information about their operating costs as a way of justifying a possible request for a price increase. In addition to the type of raw materials and equipment used to produce electric power, the number of customers available within a given area may also affect the electricity tariff. Seasonal climate change can also have a strong impact on the formulation of electricity tariffs. During the months when the weather conditions require more electricity consumption, for heating or cooling the applied tariff may reflect this increased demand for electricity. Thus, and due to the greater or lesser demand for electricity, the electricity tariff will follow this trend with higher or lower prices, respectively.

Another factor that can influence the price of electricity tariff is the type of final customer. As for residential customers, commerce or industries, it is common to have differentiated tariffs. Whether in a regulated environment or in a liberalized environment, the electricity tariff usually includes the following items: return on investments made (in production units and / or electric power transmission networks); operating and maintenance expenses; operational interests; taxes; costs of raw materials (for the production of electricity). Basically, electricity prices paid by consumers have as main components: electric energy, which includes energy and marketing prices; the costs of using the networks, (tariff of access to the networks); the CIEGs associated with energy policy and general economic interest costs that are part of the other part of network access tariffs. CIEGs are political decision-making costs, along with Network Usage tariffs, which are reflected in the tariffs for access to networks paid by all consumers [5].

The type of electricity tariffs to be applied may depend on several factors, such as: existence of a regulated or market regime, type of customer, type of production resources, existence of measurement equipment with technology that allows, for example, the introduction of dynamic tariffs, etc. There are several types of tariffs, namely:

Flat tariffs - are tariffs that, regardless of time, year period or consumer consumption, always have the same value over time;

Time-of-Use (TOU) - tariffs according to the time of use, promotes the distinction of prices throughout the day (or week), encouraging or discouraging the consumption of electricity in different periods of time;

Real-time pricing (RTP) [6] - provides the consumer with information about the current value of the electricity sales rate at any time. In order for RTP to effectively take place, it is necessary to install smart meters that can receive and send information about the cost of electricity, as well as provide the customer with information about their own behaviour;

Critical Peak Pricing (CPP) - the Critical Peak Pricing (CPP) tariffs are a relatively recent innovation, which have characteristics common to RTP rates. CPP tariffs usually start with a TOU structure, but then you add a cost related to the "critical" hours that the marketer can set from one moment to the next. CPP tariff program is similar to the contracts of interruption of load, being different that in this type of program the prices do not reach values as high as to cause the consumers to suspend almost all their consumption;

Load interruption programs - mechanism used by the system operator, when, for some reason, economic incentives fail to balance supply and demand for electricity, even for a brief period, the system operator must have the ability to restrict the use by some consumers.

\section{TARIFF DEFINITION METHODOLOGY}

The Remuneration and Tariff Mechanism (RemT) [7-8] is a decision support mechanism that is being developed to support the VPP actions in the definition of the best tariff and remuneration to apply to each of the aggregated players, regarding the VPP objectives and the individual goal of each aggregated player.

Based on the use of data-mining techniques and the consequent characterization of a certain set of electric energy consumers, the aggregating agent can propose the best tariff scheme for each class of consumers.

The tariffs definition is based on the identification of players' types and on the development of contract models for each player type. The identification of players was performed in previous works, the clustering process is performed for different numbers of clusters, from 2 to 12 , in order to enable grouping consumers according to the similarity of their consumption profiles. Also the clustering process was performed with different normalization methods applied to the data. The different clustering processes considered:

Non-normalized data [8], the clustering process is performed for different numbers of clusters, without any treatment of the data collected from the smart grid, in order to enable grouping consumers according to the similarity of their consumption profiles;

Normalized data [8], regular normalization was used. The normalization was made considering each type of consumer. The value of load corresponding to each period was divided for 
the maximum value register in that specific load in the 24 periods;

Average process, considers regular data and normalized data, for each type of consumer. The power value to be considered in the clustering process was found by averaging between the regular load values and the normalized load values for each specific load in the 24 periods;

Difference process [9], where the value of the micro production, generated in the bus associated to the same load, was subtracted from the value of the consumption of that load. This calculation is performed for loads from 1 to 17 , these are the loads, which are on buses with associated micro production;

Customized Normalization [10], normalizes data using each consumers' load value at each period divided by the largest recorded value of all loads in all periods, it was developed to improve the results achieved with regular normalization.

In this work, the customized normalization process is used. Analysing the results of previous works [8-10], it is possible to conclude that aggregation strategies have very good results, and are very useful, because they provide a good separation according to what is intended. The non-normalization grouping process has led to a clear separation between different consumers types, as it considers the absolute consumption amounts in the clustering process. The normalized data, used as formalized in (1) and (2), reveals a separation through consumption profiles, although it is not able to consider the differences in consumption quantity.

$$
\begin{gathered}
N_{c, h}=\frac{L_{c, h}}{M L_{c}}, \forall c \in c o \\
M L_{c}=\max \left(L_{c}\right), \forall c \in c o
\end{gathered}
$$

where $N$ is the common normalized load, for each consumer $c$, for each hour $h$, and $c o$ is the set of all considered consumers. $M L$ is the largest consumption value, of the consumer $c$, considering all hours.

To improve the results achieved in the previous works, the customized normalization process is used. This method normalizes data using each consumers' load value at each period divided by the largest recorded value of all loads in all periods, it is formalized in (3) and (4).

$$
\begin{gathered}
S N_{c, h}=\frac{L_{c, h}}{S M L_{h}}, \forall c \in c o \\
S M L_{h}=\max \left(L_{c o, h}\right), \forall c \in c o
\end{gathered}
$$

Where $S N$ is the load with a different normalization process, for each consumer $c$, for each hour $h$. SML is the largest consumption value recorded for all consumers at the time $h$. The proposed customized normalization method aims to combine the advantages of both previous approaches (using nonnormalized data, and regular normalization), so as to achieve consumer groups that capture both differences in the quantities of consumption, and also the trends of consumer profiles along the hours.

The methodology implemented for the definition of the different tariff structures takes into account not only the typical profile of the consumers, but also the value of the price of electricity formed in the market and also the production of wind and solar energy, it is formalized in (5) and (6).

$$
\begin{aligned}
& \text { TNew } \left._{a, b}=\text { Tb } \times \text { Factor }, \mid a, b\right] \\
& \text { Factor }=x \times \text { Pm }+y \times C c-z \times \text { Pes, } \\
& x+y+z \leq 1
\end{aligned}
$$

Where TNew is the new tariff proposed, Tb is the base tariff, from ERSE [11] and Factor is the value calculated in (2), to influence the value of the $\mathrm{Tb}$, according with player's characteristics and behaviors. [a, b] is a scaling factor, defining the allowed range of variation of the new tariff when compared to the base tariff. Pm is the electricity market price variation component, collected form the Iberian electricity market OMIE [12], Cc is the consumption variation component, referring to the representative consumption profile of each consumer group. This value is calculated using the clustering approach mentioned before. Pes is the average, of wind and solar production values, collected from REN [13]. Pes production influences the calculation formula once it is subtracted to increase the price when there is little production and decrease when there is a lot. The factors $\mathrm{x}, \mathrm{y}$ and $\mathrm{z}$ were created to influence the weight of the different elements used in the calculation formula, they can have the following values $(0.1 ; 0.25 ; 0.33 ; 0.8)$, always considering that the sum of the three factors can't be greater than 1 .

This process started with the normalization of centroids/clusters, market prices, production and consumption values and ERSE tariff base values All data was normalized to be on the same scale and for weights of $\mathrm{x}, \mathrm{y}$ and $\mathrm{z}$ make sense.

Data related to market prices was collected from OMEI from the year 2015 to 2017, data of solar and wind production was collected in the same period from REN. Regulated tariff values were collected from ERSE. A tool was developed in excel, using dynamic tables, which allowed perform several tests with different parameters selected. Three tests were made considering all data from 2015 to 2017 , data related to all days of October from 2015 to 2017 and considering the same hour (10am) of all Wednesdays of September, October and November since 2015 to 2017 . In the results analysis described in the next chapter, will analyze the results of the simulations considering all the data of the database between 2015 and 2017. The analysis could be done for any of this three simulations, all the three shown very good results.

\section{CASE STUDY}

This case study intends to show the adequacy of the proposed tariff definition methodology to solve the problem of remuneration of players with heterogeneous characteristics and behaviors. In order to test the adequacy of the method, three tests were performed with different data selection considering four types of normalization, three types of clusters, three base tariffs and five combinations for the parameters $\mathrm{x}, \mathrm{y}$ and $\mathrm{z}$. This parameters assumed different values $(0.1 ; 0.25 ; 0.33 ; 0.8)$, always considering that the sum of the three factors can't be greater than 1 . Here were analyze the results of the simulations considering all the data of the database between 2015 and 2017. 
In this case study, the values of the components that affect the new tariff, namely consumption, generation and market prices, are normalized to a scale between $[0,5 ; 1,5]$. In this way the new tariff can be up to 1,5 times higher or 0,5 times lower than the base tariff from ERSE. The base tariffs from ERSE consider three types, BTN, BTE and BTN Bi-hour, for winter and summer, working days, Saturdays, Sundays and holydays. For this case study Tb data considers BTN, winter working days.

\section{A. New tariff and ERSE tariffs criation}

The tariff definition is performed for three different clusters, with data treated with four types of normalization, with three different base tariffs and five combinations for $\mathrm{x}$, $\mathrm{y}$ and $\mathrm{z}$ parameters, respectively: a) $0.1,0.8,0.1$, b) $0.8,0.1,0.1, \quad$ c) $0.1,0.1,0.8, \quad$ d) $0.33,0.33,0.33$, e) $0.25,0.25,0.5$. When considering the different combinations of all these variables we were able to obtain 60 simulations and 1080 different tariffs. This number was very difficult to manage and analyze, so we limited the analysis data, we only consider the tariffs obtained for the winter period, on working days, thus with 180 tariffs to analyze. In Figure 1 the variation of ERSE and new tariffs is presented.

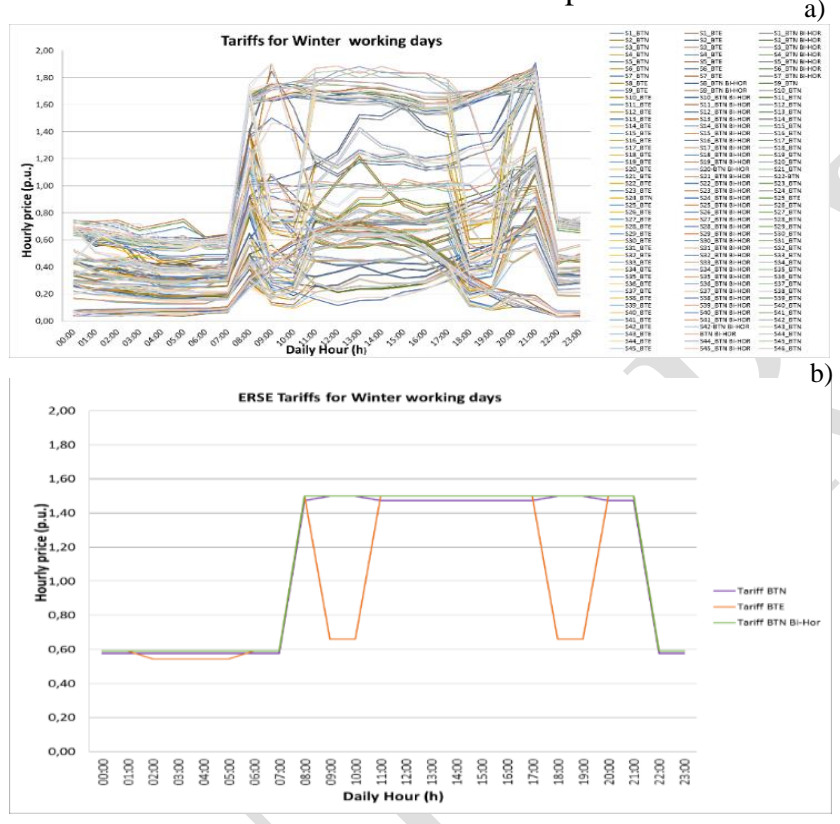

Figure 1. Price variation over the day: a) New tariff; b) ERSE tariff

Comparing the graphs a) and b) it is possible to verify than, in general, the new tariffs follow the trend of the basis ERSE tariffs, but they are adapted to meet the evolution of the renewable generation, market prices and consumption at each time, as discussed in section B.

\section{B. Variation of tariff according to the weight of the factors $x, y$ and $z$}

When giving several weights to the factors is intended to see in what way there is an adjustment of the tariff, related with the type of behavior of the player. In Figure 2 is possible to see the tariffs created for a case with three clusters (all consumers are grouped in 3 groups, and a different tariff is defined for each of the groups considering their representative consumption as a group). The customized normalization is applied, and different weights are considered for the three factors.

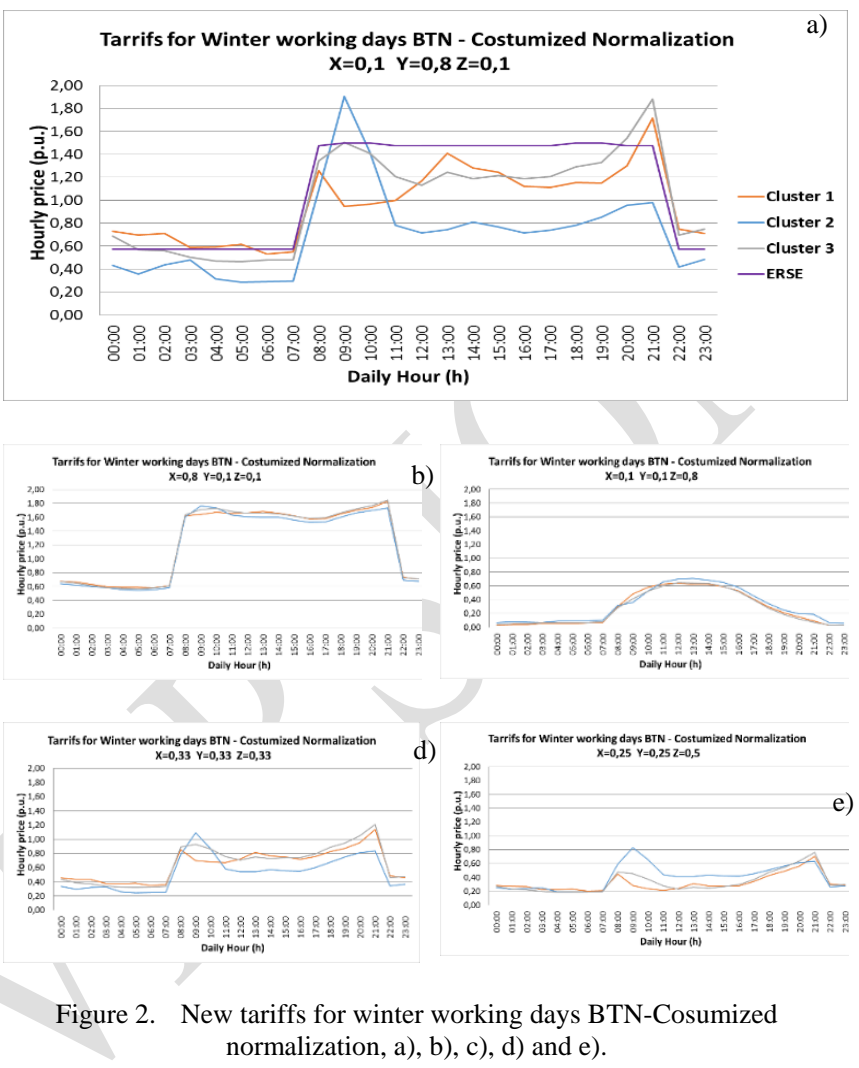

In Figure 2 it is important to analyze figure a), in which considering $\mathrm{y}=0.8$ a large weight is given to the consumption component. In this case it is visible that the defined tariffs follow the trend of the ERSE base tariff, but different variations are introduced, depending on the consumption profile of each of the three clusters, as visible by Figure 3 .

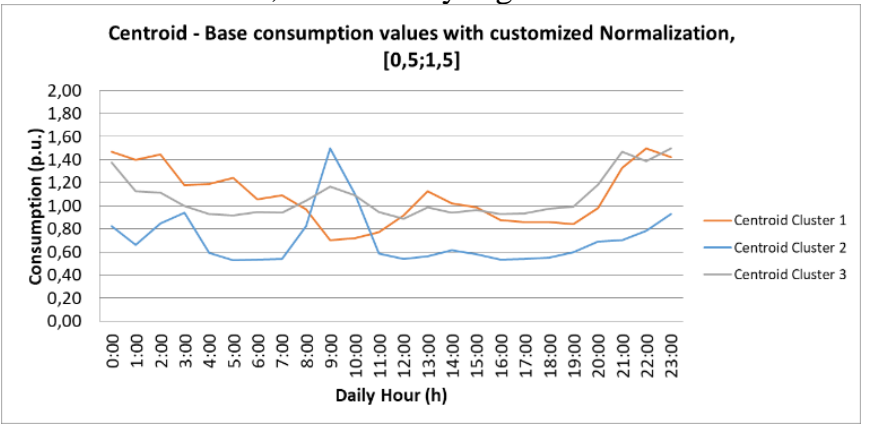

Figure 3. Representative consumption of each of the 3 clusters (cluster centroids)

\section{Energy cost analysis}

The following analysis is related to the daily energy cost. In Figure 4 it is represented the cost of energy related to cluster 1 applying the new tariff and ERSE tariff. 


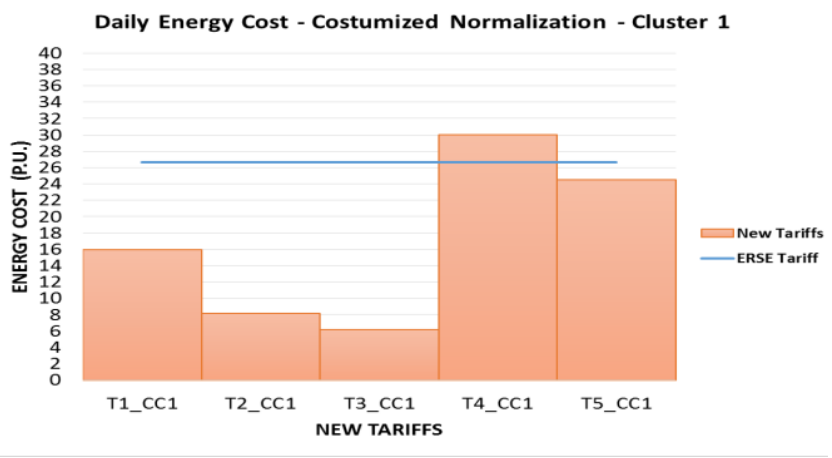

Figure 4. TNew tariffs for daily cost od energy, considering cluster 1with costumized normalization and ERSE cost value.

It is important to emphasize the simulation T1_CC1, where the same weight is attributed to all components of the tariff, see Table 1. In this simulation, the amount paid for energy is considerably lower than the cost when applied ERSE regulated tariffs. Is also important to analyze T4_CC1, where a great weight is given to the market price, in this circumstances the new tariff has a cost higher than the ERSE tariff. It is possible to conclude that a raise in market price influences negatively the price formation, making its value increase. Other important simulation is T5_CC1, were the highest weight is assigned to the consumption. The cluster consumption profile influences the price, making it very close to the price of ERSE tariff, but slightly lower. T3_CC1 is the simulation where production has the greatest weight, consequently the tariff will be considerably lower compared to the others, since there is an increase in production.

TABLE I. DAILY TOTAL COST OF ENERGY CONSIDERING CLUSTER 1 WITH COSTUMIZED NORMALIZATION AND DIFFERENT WIGHTS FOR X, Y AND Z, AND ERSE ENERGY COST.

\begin{tabular}{|c|c|c|c|c|c|c|c|}
\hline $\begin{array}{l}\text { Norma- } \\
\text { lization }\end{array}$ & $\begin{array}{c}\text { PTC } \\
\text { Cluster }\end{array}$ & $\mathbf{X}$ & $\mathbf{Y}$ & $\mathbf{Z}$ & Simulation & Tariff & $\begin{array}{c}\text { Daily } \\
\text { Energy } \\
\text { cost }\end{array}$ \\
\hline \multirow{6}{*}{$\begin{array}{l}\text { Custom- } \\
\text { ized }\end{array}$} & \multirow{6}{*}{1} & 0,33 & 0,33 & 0,33 & T1_CC1 & \multirow[t]{5}{*}{ 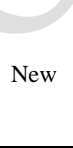 } & 15.96 \\
\hline & & 0,25 & 0,25 & 0,50 & T2_CC2 & & 8.18 \\
\hline & & 0,10 & 0,10 & 0,80 & T3_CC1 & & 6.13 \\
\hline & & 0,80 & 0,10 & 0,10 & T4_CC1 & & 29.99 \\
\hline & & 0,10 & 0,80 & 0,10 & T5_CC1 & & 24.51 \\
\hline & & - & - & - & ERSE & ERSE & 26.65 \\
\hline
\end{tabular}

In the scope of the electricity markets, there is a great freedom in the formulation of tariff schemes to be proposed to electricity consumers. It is desirable to determine transparent, fair tariffs and, above all, to promote the efficient and rational use of energy resources.

Traders and consumer aggregators may have various solutions. A tariff rate that varies over time in demand and production of electricity, or a fixed stable and clear price signals, which motivates the definition of an entire with a limited number of time periods and associated.

Therefore, a new model has been proposed to define dynamic tariffs, taking into account the value of the price formed in the market, the typical consumption profile of the customers and the production of solar and wind energy. In the formulation of the model a coefficient factor was considered.
This coefficient allows the aggregating entity to penalize the hours in which the cost of acquiring energy is higher, and to benefit the hours when the cost of electricity is lower, by reflecting the wholesale market prices in the end consumers' energy tariff. Moreover, the proposed tariff definition model also increases the price in times of higher consumption, in order to contribute towards the reduction of consumption peaks, and it also decreases the tariff value when the amount of renewable generation increases, in order to potentiate the maximum use of renewable generation.

The application of electric energy tariffs should be simple and transparent, to transmit economic signals of cost and also induce the final consumers to be proactive agents. Leading them to adopt demand response measures, taking conscious and responsible options on their consumption of electricity.

This is the era of information technology and electronic communications, therefore metering systems as smart metering will allow the implementation of this tariffs, aiming at competitiveness among marketers, promoting the reduction of electric power purchase prices by consumers.

\section{REFERENCES}

[1] Praça, I., Ramos, C., Vale, Z., Cordeiro, M. "MASCEM: A Multi-Agent System that Simulates Competitive Electricity Markets", IEEE Intelligent Systems, 18, 6, pp. 54-60, 2003

[2] Koritarov, V. "Real-World Market Representation with Agents: Modeling the Electricity Market as a Complex Adaptive System with an AgentBased Approach", IEEE Power \& Energy magazine, pp. 39-46, 2004

[3] Severin, B. "Customer Risk from Real-Time Retail Electricity Pricing: Bill Volatility and Hedgability", NBER Working Paper No. 12524, September 2006, and Energy Journal, 28[2], pp. 111-30, 2007.

[4] Lohrmann, B.; Kao, O.; "Processing smart meter data streams in the cloud", Innovative Smart Grid Technologies [ISGT Europe], 2nd IEEE PES International Conference and Exhibition, pp. 1-8, 5-7 December 2011.

[5] Erse; "Nota Informativa - Composição dos preços de eletricidade para 2013", Entidade Reguladora dos Serviços Energéticos, Fevereiro, 2013.

[6] Vickrey, William; "Responsive pricing of public utility services", The RAND Corporation, vol. 2(1), pp. 337-346, Spring, 1971.

[7] Ribeiro C., et al., " Intelligent Remuneration and Tariffs in for Virtual Power Players", IEEE PowerTech (POWERTECH) Grenoble, France, 16-20 June, 2013

[8] C. Ribeiro., et al., "Data Mining approach for Decision Support in real data based Smart Grid scenario" IATEM, 2015

[9] Ribeiro C., Pinto T., Vale Z., Baptista J. (2018) Data Mining for Prosumers Aggregation considering the Self-Generation. In: Distributed Computing and Artificial Intelligence, 14th International Conference. DCAI 2017. Advances in Intelligent Systems and Computing, vol 620. Springer, Cham.

[10] Ribeiro C., Pinto T., Vale Z. (2016) Customized Normalization Method to Enhance the Clustering Process of Consumption Profiles. In: Lindgren H. et al. (eds) Ambient Intelligence- Software and Applications - 7th International Symposium on Ambient Intelligence (ISAmI 2016). Advances in Intelligent Systems and Computing, vol 476. Springer, Cham.

[11]ERSE, Entidade Reguladora dos Serviços Energéticos, , webpage, available:

http://www.erse.pt/pt/electricidade/tarifaseprecos/2017/Documents/TAct ividade/Precos.ATIVORD2017.pdf

[12]OMIE, Iberian market operator, webpage, available: http://www.omie.es/files/flash/ResultadosMercado.swf

[13]REN, Portuguese National Energy Networks, webpage, available: http://www.centrodeinformacao.ren.pt/EN/Pages/CIHomePage.aspx. 